\title{
Um estudo de caso acerca do Conselho Municipal de Defesa do Meio Ambiente de Santa Maria/RS
}

Gilmar Tadeu Bolzan ${ }^{1}$

\section{Resumo:}

O presente artigo analisa as dinâmicas formativas e relacionais ocorridas no Conselho Municipal de Defesa do Meio Ambiente de Santa Maria/RS. Concebido para ser um mecanismo democrático que efetivasse a participação do cidadão no âmbito municipal no tocante às questões de meio ambiente, o conselho passou a espelhar uma séries de relações de poder que ilustram o distanciamento entre as ações e interesses do poder executivo e os interesses da sociedade civil.

Palavras-chave: democracia; meio ambiente; sociedade civil.

\section{Abstract}

This article analyzes the formative and relational dynamics occurring in the City Council Environmental Defense Santa Maria / RS. Designed to be a democratic mechanism that efetivasse citizen participation at the local level with respect to environmental issues, the council passed the mirror a series of power relations that illustrate the gap between the actions and interests of the executive and the interests of civil society.

Key-word: democracy, the environment, civil society

As mudanças ocorridas nas políticas de meio ambiente no Brasil após a Constituição de 1988 foram marcadas, entre outros fatores, pela descentralização e pela criação de mecanismos institucionais de participação, visando o controle social sobre a gestão, fiscalização e deliberação de políticas ambientais. O deslocamento dessas políticas para o nível local, num país com uma estrutura federativa, resultou na transferência para o município as principais decisões sobre essas políticas. Novas relações decisórias foram implantadas a partir do diálogo entre entidades governamentais e representantes da sociedade civil. Porém, apesar da participação popular e do controle social serem considerados fatores indispensáveis para a democracia representativa e para a efetivação das políticas

\footnotetext{
${ }^{1}$ Especialista em Pensamento Político Brasileiro pela UFSM e Mestre em Sociologia pela UFSC.
}

Latitude, vol. 7, n², pp.169-190, 2011

DOI: https://doi.org/10.28998/2179-5428.2011020 
ambientais, a consolidação destes fatores permanece ainda como um grande desafio.

Isso ocorre, em parte, devido às falhas na intermediação entre a sociedade civil e o Estado. Historicamente, essa função tem sido exercida no parlamento e, em certo sentido, vinculada aos partidos políticos, que, na sua grande maioria, sempre tenderam a estar mais próximos do Estado e distantes da sociedade civil. Esse distanciamento somente é encurtado nos períodos eleitorais, por uma questão estratégica com fins a busca do voto.

Essa crise política de representação ou a falta de representação da sociedade civil junto ao Estado tem norteado a busca de alternativas, dentre as quais, a intervenção nas políticas públicas, através dos conselhos gestores, atividades até então restritas à classe política.

No processo de redemocratização do Brasil, no final da década de 1970 e início dos anos 1980, foi que alguns movimentos sociais e intelectuais passaram a questionar quais os mecanismos necessários para constituir um Estado democrático e realmente público, tendo tão somente a democracia representativa enquanto instrumento representativo da sociedade civil.

Os conselhos gestores, desse modo, surgiram com o propósito de ampliação desse modelo de democracia. Contudo nossa tradição política não é nada inspiradora para a formação de um Estado democratizado e descentralizado: o clientelismo, o personalismo e o patrimonialismo, são alguns dos vícios políticos que estão enraizados na cultura política brasileira e tendem a serem obstáculos para o êxito desses novos mecanismos de gestão pública (Gohn: 2000). Além disso, Fedozzi (1999), alerta que a descentralização política e administrativa, originada pela constituição de 1988, necessariamente não significa democratização, dado a possibilidade de manutenção de determinados "vícios políticos", que também se descentralizariam, e passariam a atuar em outras esferas administrativas. Desse modo, o processo de descentralização não tem facilitado a participação das comunidades na tomada de decisões relacionadas às políticas públicas, já que a descentralização, por si só, não pode mudar as relações de poder.

Nessa direção, identifica-se um vasto repertório de argumentos sobre as possibilidades de participação social nos processos decisórios do Estado que, apesar das diferenças e focos de análise, ora incentivam ora desqualificam essa participação.

Por um lado, considera-se que, mesmo que os conselhos gestores tenham sido gerados através de uma determinação legal originada na esfera federal, os mecanismos de participação que eles engendram tendem a erodir as formas tradicionais de poder e propiciar um maior controle social sobre as políticas públicas. (Cohen, 1997, Luchmann, 2002a). 
Por outro lado, considera-se a sociedade civil despreparada para participar enquanto protagonista das políticas públicas alegando-se que apenas uma minoria dos cidadãos está interessada e engajada na vida política (Dahl, 1992); que somente a burocracia ou o setor político estariam capacitados para tal finalidade; que a sociedade torna-se um empecilho na tomada de decisões, seja por seu posicionamento crítico diante das propostas (ou ausência das mesmas) do executivo, ou mesmo pela demora em tomar decisões (Moroni: 2005) ou, ainda, que a institucionalização da participação tende a gerar uma equivocada consciência de democracia.

Amparado pela revisão da literatura sobre a temática da participação e controle social no Brasil, este artigo pretende expor sinteticamente pesquisa realizada no mestrado que teve como objeto o Conselho Municipal de Defesa do Meio Ambiente do município de Santa Maria/RS.

Metodologicamente foi utilizado, na análise documental, as Atas e documentos oficiais, bem como publicações acerca da temática do jornal "Diário de Santa Maria". Foi aplicado também um questionário a todos os membros do conselho, em uma análise estatístico descritiva, com fins a ter um perfil de todo conselho a partir do ponto de vista de seus integrantes. Outro ponto investigativo importante foi a realização de entrevistas semi-estruturadas com alguns membros que, por sua atuação, historicamente se destacaram no conselho. O roteiro foi montado a partir da análise dos temas, discussões, encaminhamentos e resolutividade registrados nas atas oficiais do Conselho. Destaca-se ainda a observação nas reuniões do Conselho que oportunizaram a identificação dos atores, os mecanismos de funcionamento e principalmente situações que não são registradas em Atas, mas que compunham uma rede de relações que auxiliaram peremptoriamente na análise sobre este objeto.

O tempo de pesquisa junto ao CONDEMA correspondeu ao período de 1998, ano em que foi criado, até a última reunião de 2007. Embora a pesquisa tenha sido finalizada neste ano, foram acrescidos alguns dados informacionais pertinentes ocorridos em 2008 que complementaram o trabalho de pesquisa. Ao longo desses dez anos de pesquisa foi possível observar que o conselho passou por diversos processos de transformação.

Uma das dificuldades da presente pesquisa que merece destaque, e que também corresponde a uma crítica ao próprio conselho, é relacionado a dificuldade que a presente pesquisa teve no levantamento de atas e documentos oficiais. Uma parte estava disposta na Secretaria de Proteção Ambiental, entretanto foi necessário recorrer a diversos integrantes que dispunham de cópias em seu acervo pessoal desse importante componente histórico do próprio conselho. A falta de uma maior preocupação e desleixo para com o arquivamento dessa documentação remeteu a constituir um obstáculo na própria "leitura" sobre o conselho. 
A pesquisa, deste modo, se deu por meio de análise da produção teórica a respeito do tema específico, mas, também, dos elementos que "gravitam" ao seu redor, componentes imprescindíveis para análise do CONDEMA de Santa Maria. $\mathrm{Na}$ parte de investigação empírica, ressalta-se, que a ausência de Atas e dificuldades de "encontrar" documentos oficiais dificultaram de certo modo uma leitura linear do Conselho, no entanto, através das entrevistas e das poucas matérias jornalísticas realizadas sobre esses momentos, foi possível contornar essa dificuldade e esclarecer determinados momentos importantes de sua atuação.

\section{A EXPERIÊNCIA DO CONSELHO DE MEIO AMBIENTE DE SANTA MARIA/RS}

Do ponto de vista teórico, o aumento da percepção dos problemas ambientais, seja pelos técnicos ou pelos movimentos ambientalistas, resultou em novas reivindicações além das demandas tradicionais (direitos humanos e justiça social) e contribuiu consideravelmente "para gerar uma cultura politica mais plural e para dar sentido aos processos de governabilidade democrática" (Leff: 2004, p.62). Além disso, tem fomentado, através do fortalecimento de projetos de gestão ambiental articulados com a sociedade, "um novo contrato social entre o Estado e a sociedade civil"(idem, p.63), instaurando, assim, novos procedimentos de gestão pública que possam dirimir, de forma pacífica, os conflitos ocasionados na relação entre os interesses dos diversos tipos de agentes econômicos e do restante da sociedade.

A perspectiva descentralizadora da Constituição brasileira que outorga competência aos municípios para legislar sobre assuntos locais e cria mecanismos de participação social, também impulsionou a discussão sobre os problemas ambientais e sobre o uso de recursos naturais que até então estava sobre competência da União. E nesse contexto, os Conselhos de Meio ambiente foram criados.

Os Conselhos Municipais de Defesa do Meio Ambiente (CONDEMA) são deliberativos e é composto por 21 membros titulares e igual número de suplentes, conforme diretrizes do Departamento de Planejamento e Coordenação da Política Ambiental/ Presidência da República (DEMAR/PR). Dez membros são representantes do Poder Público, nas esferas Federal, Estadual e Municipal e onze são representantes da Sociedade Civil, representantes de sindicatos, associações comunitárias, fundações, conselhos, etc.

Em relação a sua estrutura de funcionamento os conselheiros têm um mandato de dois anos, podendo ser prorrogável por mais um período, conforme decisão da entidade que representa. As entidades participantes podem ser substituídas por decisão do Conselho, com maioria de votos e em qualquer época. Não existe qualquer tipo de remuneração aos seus integrantes, sendo que seu 
exercício corresponde a uma prestação de serviços relevantes ao município. O CONDEMA possui um núcleo de coordenação responsável pelas convocações, organizações e coordenações dos seus encontros, e é composto por dois membros do grupo I - Poder Público, e três membros do grupo II - Entidades Civis.

É importante destacar a motivação econômica² existente para a criação dos CONDEMAs. O licenciamento ambiental e a cobrança de taxas somente são possíveis naquelas prefeituras que tiverem um Conselho Municipal de Meio Ambiente em atividade e de acordo com as diretrizes do DEMAR. O que significa um aumento na arrecadação municipal e, conseqüentemente, na possibilidade de um maior investimento nas políticas ambientais aos municípios que seguem estas determinações. O próprio repasse de verbas aos Municípios, em muitos casos, está condicionado a existência desses mecanismos de fiscalização e gerenciamento de políticas públicas.

As principais finalidades do CONDEMA são:

1. formular as proposições que visem a manutenção, melhora e, se necessário, recuperação da qualidade ambiental do município;

2. elaborar o estudo que propicie a definição de normas e procedimentos para a proteção ambiental do município, a promoção e colaboração na execução de programas intersetoriais para sua proteção ambiental;

3. colaborar em campanhas de perfil educacional referente ao meio ambiente, problemas de saúde e saneamento básico;

4. e defender a obrigatoriedade, nos estabelecimentos municipais de ensino de nível fundamental e médio, os ensinamentos básicos que propiciem ao aluno o conhecimento sobre Educação Ambiental para fins de sua conservação e recuperação.

As Conferências Municipais de Meio Ambiente, incumbidas de subsidiar essas finalidades do CONDEMA, são fóruns deliberativos que contam com a participação de todos os segmentos sociais na avaliação e busca de alternativas para a questão ambiental da cidade. São convocadas pelo Prefeito e têm uma

2 Existe uma "motivação" econômica legalmente instituída para a criação de muitos Conselhos. No caso dos CONDEMAS, ela está presente na resolução 237, de dezembro de 1997, artigo 6 do Conselho Nacional de Meio Ambiente - CONAMA (Carvalho, 2004). O licenciamento ambiental e a cobrança de taxas referente aos mesmos, só é possível aquelas prefeituras que tiverem um Conselho Municipal de Meio Ambiente em atividade, e consonantes as diretrizes do DEMAR. O que infere aos municípios que seguem estas determinações em um aumento na arrecadação municipal e, consequentemente, na possibilidade de um maior investimento nas políticas ambientais. O próprio repasse de verbas aos Municípios, em muitos casos, está condicionado a existência desses mecanismos de fiscalização e gerenciamento de políticas públicas.

Latitude, vol. 7, n², pp.169-190, 2011. 
periodicidade não maior do que dois anos, e não podem ser realizadas em ano eleitoral.

Entretanto, na prática, os Conselhos de Meio Ambiente não tem cumprido com o propósito de sua criação. Existe desequilíbrio entre a retórica e a prática nos assuntos relativos ao meio ambiente, sobretudo no que se refere ao fato de que o "poder executivo age normalmente tendo em vista um horizonte limitado (o fim de seu mandato)" (Gutberlet,1996, p. 41), e estabelece políticas que 'maquiam' os problemas, tratando de suas conseqüências, sem, efetivamente, atacar suas causas. Desse modo, acaba predominando a "opção pelo desenvolvimento desvinculado de questões ambientais e sociais, o que, conseqüentemente, gera poucos esforços políticos para reverter o atual quadro de degradação ambiental e desigualdade social". (idem, p. 42)

Através das entrevistas com os conselheiros bem como das análises das Atas e das observações das reuniões do CONDEMA na cidade de Santa Maria/RS, foi possível identificar, entre outros aspectos, duas crises que culminaram com a renúncia de seu núcleo central: uma crise relacional externa, devido a uma relação conflituosa com o poder executivo; e uma crise relacional interna, que envolveu diretamente os seus representantes.

Em relação à crise entre o Poder Executivo e o Conselho ocorreram três episódios importantes. O primeiro deles corresponde ao não cumprimento de um Termo de Conduta Ambiental, assinado junto a Promotoria Pública, onde não se colocaria mais lixo em uma região da cidade e se recuperaria o ambiente degradado do local. O fato é que o Executivo não cumpriu o acordo o que gerou uma grande crise relacional e, por meio do Ministério Público, redundou em vários Inquéritos Criminais. O segundo episódio, ocorrido em julho de 2005, refere-se à retirada a revelia do conselho de 150 mil reais do Fundo Municipal de Meio Ambiente, além do não repasse de 20 mil anuais referente à manutenção do CONDEMA. Essa crise culminou com a primeira renúncia do núcleo e envolveu, além do Ministério Público, o Poder Legislativo Local. E o terceiro episódio, mais de natureza de "competências", foi a que o Executivo relutou em aceitar que uma resolução que estabelecia limites de emissão de radiação de torres de telefonia celular tivesse poder de Lei. Ao longo dessa crise houve a mudança de Secretário de Proteção Ambiental e representante do executivo no Conselho e teve como resultado favorável ao Conselho, onde a resolução passou a ser aplicada como Lei.

A implantação de políticas ambientais geralmente é percebida, pelos governos, como um enorme investimento com baixo "retorno eleitoral", e por esse motivo tende a ser considerada menos prioritária. As trocas de secretários de Meio Ambiente durante o período estudado (em sete anos de mandato do último prefeito, passaram nada menos do que seis secretários), ilustra bem essa situação. Nesse período, os Secretários de Meio Ambiente do município tiveram pouco apoio institucional, tanto do Conselho quanto do próprio Prefeito, e sempre que as 
relações internas se estremeciam, sobretudo pela própria condição do gestor municipal descumprir as deliberações deste órgão, optava-se pelo caminho mais fácil, ou seja, a troca de seu representante. Em uma clara tentativa de acalmar ânimos e ganhar tempo.

Já a crise interna está relacionada ao próprio ambiente interno desses fóruns de interlocução e deliberação. Devido à convivência entre diferentes interesses e pontos de vistas, os conselheiros deliberaram sobre posições que nem sempre convergiam. Neste aspecto, o desgaste nas relações do CONDEMA foi se acentuando ao longo do tempo, e alguns fatores foram identificados como centrais: a dificuldade de se estabelecer um ambiente democrático, no que pese principalmente ao respeito a opiniões divergentes, a busca de "poder pessoal" e a pouca resolutividade do conselho.

Gohn (2004) acentua o risco em que estão expostos os conselhistas, pois, se essa experiência pode transformá-los em cidadãos ativos, politizados e com uma visão critica da realidade, de outro modo, em razão de se tornarem meros executores de missões, de atuações individualizadas e personalistas, passariam a ser simples tarefeiros. Desfigurando, assim, um dos princípios centrais da criação desses fóruns, de ser uma escola de cidadania.

Por tudo isso, existe uma grande chance dos conselhos - sobretudo pela falta de resolutividade de suas decisões - se tornarem peça fictícia da administração pública, existindo apenas do ponto de vista da Lei. O atrelamento e o controle governamental nos conselhos têm legitimado um conjunto de ações e medidas bastante questionáveis quanto a sua natureza ética e política. Nesse caso, este importante instrumento democrático passaria a ser unicamente "instrumentos de acobertamento de fraudes do sistema político ou do privilegiamento de determinados setores empresariais" (Luchmann: 2002 p.13).

Neste ponto, é preciso tratar aqui também da relação entre o CONDEMA e o Poder Legislativo. O Poder Legislativo de Santa Maria esteve presente nos momentos de crise entre o CONDEMA e o Executivo Municipal, inclusive com o aumento considerável no PPA de receita para sua manutenção. Isso ocorreu no caso específico da retirada do dinheiro do fundo e da falta dos repasses legalmente instituídos para a sua manutenção.

Essa relação, porém, institucionalmente vai muito além. Aos conselhos gestores também se tem atribuído a função de serem órgãos consultivos nos processos de matéria legislativa, pois os projetos de lei podem ser oriundos do Poder Legislativo, Executivo ou mesmo por iniciativa popular (com abaixo assinado de pelo menos $5 \%$ do eleitorado). A critério de melhor entendimento desse processo, passaremos então a expor o seu tramite regimental.

O Art. 162, do Regimento Interno da Câmara de Vereadores de Santa Maria, prescreve que após um Projeto de Lei Ordinária ou Complementar ser protocolado, ele segue para análise da Procuradoria Geral da Câmara e Assessoria 
Técnica, cujo parecer é de caráter opinativo. Na seqüência, a proposição segue para a Comissão de Constituição de Justiça, essa sim com poder de arquivamento, no caso de considerar a matéria em questão inconstitucional. Seguindo o seu tramite o projeto deve passar por uma Comissão Permanente Temática. São elas: Comissão de Educação, Saúde e Meio Ambiente; Comissão de Desenvolvimento Econômico e Serviços Públicos; Comissão de Orçamento e Finanças; e Comissão de Integração e Assuntos Internacionais. No caso do assunto tratado ser de competência de mais de uma comissão ele terá de passar por todas aquelas que lhe são pertinentes. As comissões são formadas pelos Vereadores, a Procuradoria é ocupada pela indicação da Mesa Diretora de um profissional da área da advocacia e a Assessora Técnica por um Assessor Técnico concursado.

Já no Art. 163 do próprio RI da CMVSM, está definido que quando a proposição ensejar a formação de uma Comissão Especial ela não passará pelas Comissões Temáticas. Podendo cada comissão realizar uma Audiência Pública, convidando autoridades e sociedade civil representativa e população, se assim considerar necessário para análise do projeto em trâmite (Art. 229-231). A última etapa dessa tramitação de um projeto de lei é o plenário e, em caso de aprovação, a sanção pelo Prefeito.

Não consta no referido regimento nada sobre os conselhos gestores, e na Lei Orgânica do município, no capítulo referente aos Conselhos Municipais (Art. 56), cita que sua finalidade é de "auxiliar a administração na orientação, interpretação e julgamento de matéria de sua competência". Na Lei Municipal 4167/98, que criou o CONDEMA, em seu artigo primeiro, o define como "órgão deliberativo, fiscalizador e de assessoramento dos Poderes Municipais de Santa Maria em caráter permanente, nas gestões referentes ao equilíbrio ecológico e ao combate às agressões ambientais em toda área do Município de Santa Maria".

Embora não cite explicitamente a obrigatoriedade de um projeto de lei que trate da questão ambiental passar pelo CONDEMA, subentende-se que sua definição como instrumento de "assessoramento aos Poderes Municipais" cumpra essa função. Na opinião da Assistência Jurídica da Câmara de Vereadores, todo o PL (Projeto de Lei) que trate de questão relacionada teria de passar pelo seu respectivo conselho.

Se historicamente tem-se a análise e o parecer sobre diversos PL, como é o caso do PL 5537 e 5539/99, de autoria do Executivo, que tratavam da criação de novos cargos para atuarem na secretaria de saúde e meio ambiente, ou nos projetos 6412/03 e 6423/03, ambos de autoria do Legislativo, que tratam respectivamente sobre o destino dos resíduos contaminados domiciliares e o que obriga as empresas que comercializam baterias e pilhas a instalarem recipientes para coletagem destes produtos. O fato é que nem todo o PL que trata da questão ambiental tenha passado pela consulta ao CONDEMA e, nos últimos anos, vários projetos que abordaram esta temática não tramitaram por essa instância consultiva. 
Um exemplo disso ocorreu na reunião de agosto de 2007 (Ata 08/073), após sugestão de um conselheiro de envio de Moção de Apoio a um Vereador pelo Projeto de Lei que trata dos descartes das lâmpadas fluorescente, o Coordenador do Conselho questionou porque esse projeto não passou pelo CONDEMA. Daí infere-se ao menos duas hipóteses: Falha no processo legislativo (por descuido e/ou ignorância dos tramites devido) ou por deliberação (entendimento de que os projetos não devam receber parecer exarado por tal órgão).

No que tange a relação direta entre os Vereadores e os Conselhos, não é incomum observar críticas dos parlamentares a estes órgãos. Quando estava em processo um convênio entre a Prefeitura Municipal e o Hospital de Caridade Astrogildo de Azevedo para a gestão da Casa de Saúde, o Conselho de Saúde foi alvo de várias críticas por parte de alguns parlamentares. Na reunião da Comissão Representativa do dia 10 de janeiro de 2008 (Ata 02/08 - CMVSM ${ }^{4}$ ), este conselho chegou a ser acusado de estar há muito tempo atrapalhando a saúde do município e, deste modo, prestar um desserviço a sociedade local, colocando em risco o própria efetividade e sobrevivência do convênio. A crítica chegou a tal ponto de um vereador de oposição acusar os coordenadores do Conselho de Saúde de serem criaturas criadas pelo partido no poder que sobre eles perdeu total ingerência, como "monstros" criados que se voltam contra seus criadores, atrapalhando a própria atual administração.

Assim, através deste exemplo, é possível observar mais acerca desta relação entre esses dois modelos de gestão que estão postos institucionalmente em nossa sociedade, a saber: um modelo tradicional de democracia representativa, onde a escolha é feita por meio de um processo eleitoral; e um novo modelo que se "insurge" com uma proposta de democratização da gestão pública, onde seus membros são indicados pelas instituições que se fazem presentes, contemplando a participação da sociedade civil e órgãos governamentais. E, embora o parlamento possa ter se eximido de algumas responsabilidades que geralmente só geram ônus, como no caso dos conselhos municipais de transportes que decidem sobre os reajustes nas passagens do transporte coletivo urbano, a presença dos conselhos tem se tornado, para muitos representantes do modelo de democracia liberal, um elemento opositor e concorrente.

Se, contudo, essa é a relação junto ao Legislativo, muito difere de sua relação para com o Ministério Público. A presença de citações do mesmo nas Atas do CONDEMA demonstra uma relação muito mais afinada do que com os outros poderes. Já nos primeiros anos de sua instauração, na reunião de 03 de setembro de 1999 (Ata 09/99), consta uma reunião com o Promotor para tratar da preocupação ambiental da época, o caso do lixão da caturrita. Como visto, este tema teve uma

\footnotetext{
${ }^{3}$ Ata número 08 de 1997 do Condema.

${ }^{4}$ Ata número 02 de 2008 da Câmara de Vereadores de Santa Maria - CMVSM.
} 
relação bem intensa entre este conselho, a Promotoria, o Executivo e a própria empresa de coleta de lixo. Do mesmo modo que os outros episódios de crise com o Poder Executivo, como já amplamente apresentado aqui, também tiveram uma forte presença do MP.

Contudo, esta relação com o MP não se deu somente com a crise com o Executivo municipal. No caso do projeto do Governo do Estado de construção de um Hospital Regional, o CONDEMA cobrou do MP a realização de todos os estudos previstos pela legislação ambiental. Uma vez que o local escolhido para tal empreendimento passou a ser questionado pelo conselho por tratar-se de uma área do distrito industrial, onde existe até uma empresa que trabalha com reposição de baterias de veículos automotores (Ata 08/05). Após este polêmico episódio foi escolhido outro local para a construção desse hospital, mas de fato esta obra sempre pautou mais na agenda político-eleitoral, pois até hoje não saiu do papel.

É provável que a própria similaridade em sua constituição, pois ambos foram oriundos da Carta Magna de 1988, torne a relação entre o CONDEMA e o Ministério Público de maior sintonia. O entrosamento constatado difere consideravelmente da relação com o Poder Executivo e com o Poder Legislativo, onde o conflito se fez presente. Com efeito, o MP não foi somente um aliado de defesa deste Conselho, mas também recorreu a ele, através de seus estudos técnicos, para amparar legalmente seus inquéritos.

Observa-se que esta relação com o MP se apresenta muito próximo do ideal, do modo em que, em tese, se configuraria como uma relação autônoma e independente de interação externa, embasada na defesa dos interesses recíprocos. No caso oposto, a relação para com os Poderes Executivo e Legislativo, observada neste caso do CONDEMA, nos transmite em certos momentos a idéia de concorrência e de subordinação. Levando-se em conta o fato já citado de que tanto os conselhos como o ministério público são mecanismos institucionais recentes, é possível que ambos sofram críticas e se crie certa resistência no que se refere a sua atuação e consolidação. Se no caso do CONDEMA esta "resistência" se apresentou por meio dos Poderes Executivo e Legislativo, no que tange ao Ministério Público, ela provém também do Poder Judiciário que questiona os seus "superpoderes". 
A seguir apresentamos um quadro exemplificando a relação exposta acima:

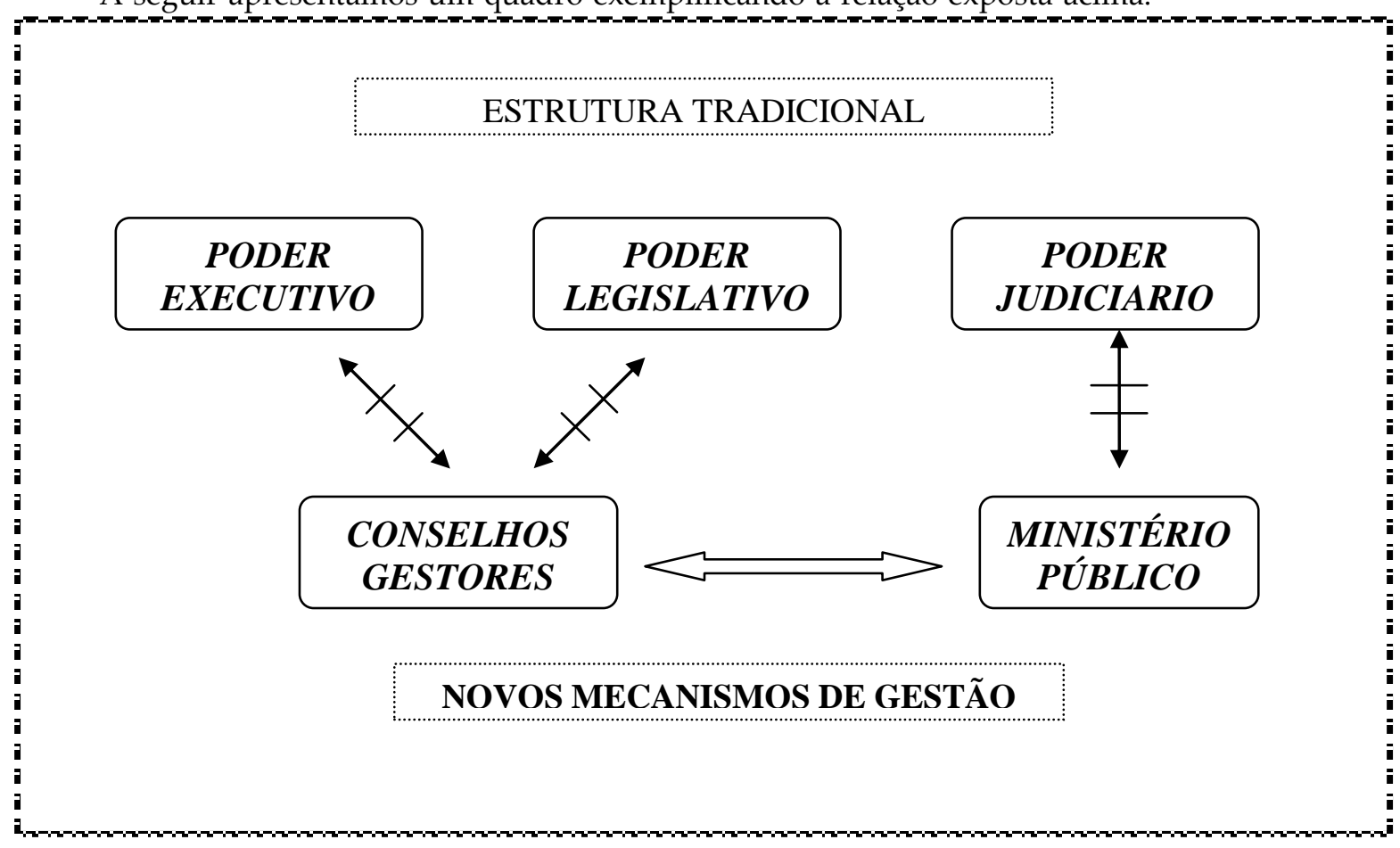

\section{O CONDEMA VISTO POR SEUS REPRESENTANTES}

Aqui perfaz a análise a partir da visão dos seus representantes, contemplando a aplicação de um questionário e a realização de entrevistas.

A aplicação do questionário teve como objetivo fazer um levantamento sobre o que pensam os conselheiros sobre o próprio conselho. Buscando uma visão geral, foi aplicado o questionário ao representante de todas as 21 entidades, entretanto, apesar de várias tentativas entregando o questionário nas reuniões do conselho e/ou mesmo utilizando o correio eletrônico, apenas 16 representantes responderam-no. Esta "ausência" da participação de 5 entidades, em meu entendimento, não compromete o objetivo desta pesquisa, mas deve ser considerado com um importante dado, pois reflete a própria questão da participação das entidades nos Conselhos.

Assim, no que se refere aos dados relativos a formação analisada do CONDEMA, é possível observar que seu perfil é constituído por maioria masculina, com faixa etária predominante entre os 41 e 60 anos e, com pouco mais de $60 \%$, são casados. Ressaltamos, ainda, o nível de escolaridade dos conselheiros e a questão partidária, tendo ampla maioria de membros com ensino superior e sem 
filiação partidária. Neste aspecto, correspondente a condição ideológica, a posição predominante é a não definição ideológica, aos que se definiram, a opção de esquerda predominou.

No outro aspecto investigado, referente ao que pensam sobre o conselho, a ampla maioria definiu que o retorno dado a entidade a que representa é feita por meio de reuniões. Entretanto, chama-nos a atenção aqui o fato de que também houveram casos de que não é dado nenhum tipo de retorno referente a sua "representatividade" no conselho.

Inobstante o fato de o considerarem como um conselho atuante (se autoanalisarem da mesma forma) e cuja questão presencial nas reuniões estando dentro do esperado, os conselheiros, em posição majoritária, apontaram que existe pouca participação, restringindo-a aos "mesmos de sempre". Disso desdobram-se vários fatores que influenciam nessa pouca participação, que vão desde a questão da falta de tempo e imposição de pautas até a falta de conhecimentos específicos sobre os temas relevantes que por lá são tratados. Esse processo "impositivo" e de "falta de conhecimento" é somado a opção que apontou a falta de relevância dos temas tratados nas reuniões do Conselho. O centralismo do núcleo, com menos escolhas, foi outro fator que desestimula a participação. Mas é preciso destacar que essas últimas opções refletem a enorme crise interna que vivia o conselho quando foi aplicado esse questionário, onde o debate estava muito agressivo e centrado em questões que envolviam um alto teor de pessoalidade.

Outro ponto interessante que reflete essa visão de que existem ainda dificuldades em seu funcionamento é a opção feita quando a questão apresentada foi reflexiva sobre o próprio conselho. Ao definirem majoritariamente que ele melhorou ao longo do tempo, mas que precisa amadurecer como Conselho e, sobretudo, por nenhum conselheiro tê-lo definido que ele é "ciente de suas funções e que cumpre com as obrigações de um conselho deliberativo" é no mínimo sintomático. Provavelmente corresponde ao fato de que em sua visão houve ao longo do tempo uma evolução, mas que ainda se encontra muito longe do ideal.

Acerca da relação com a população e com a imprensa fica clara a posição de que o CONDEMA carece de reconhecimento. No que tange a imprensa, todas as opções feitas pelos pesquisados revelam essa dificuldade de exposição na mídia, o que, muito provavelmente, influencia negativamente também no reconhecimento para junto à população.

A pouca resolutividade nas decisões do conselho é outro ponto a ser observado aqui. O curioso é que majoritariamente os conselheiros consideram que tanto a sociedade civil quanto o poder executivo tem pouca influência interna. $\mathrm{O}$ que, segundo essa visão, pode ser um índice de que o conselho está "livre de pressão" para decidir, mas as suas deliberações nem sempre são passiveis de aplicabilidade. 
A propósito, deliberar sobre políticas públicas de meio ambiente é considerado pela maioria como principal função do conselheiro do CONDEMA. A fiscalização e a análise de projetos de lei que versem sobre o tema também são apontadas aqui. No entanto, é a definição de alguns de que o papel do conselheiro corresponde a servir de suporte institucional ao poder executivo é o que mais chama a atenção. Se por um lado essa posição pode ser entendida no que corresponde ao conselho ser um órgão de assessoria aos poderes municipais, conforme prevê a legislação, ela também pode passar a visão de atrelamento, falta de independência e/ou subordinação, em um processo hierarquizado.

A elaboração das entrevistas com um roteiro semi-estruturado, com algumas questões chaves, não impediu aos entrevistados discorrerem sobre outros assuntos. Como já foi mencionado anteriormente, foram escolhidas algumas pessoas que, independente do período que participaram do Conselho, se destacaram por sua participação. Neste sentido, é importante destacar que as declarações desses sujeitos devem ser compreendidas em função do contexto de sua participação e do papel institucional que elas representam.

As três questões que vamos trabalhar nesse capítulo referem-se ao saber acerca do cumprimento da finalidade deste conselho e sobre as crises relacionais (externa e interna) existentes neste período de análise. Outros aspectos que foram levantados nas entrevistas estão dispostos ao longo do trabalho e buscaram esclarecer pontos que por falta de documentos e/ou informações ficaram obscurecidos.

A primeira questão apresentada que correspondia em saber se, conforme propósito previsto na constituição de 1988, o CONDEMA vem cumprimento com sua finalidade de democratizar a gestão pública, foi observado que as visões acerca do cumprimento da finalidade do Conselho estudado não são consensuais. Se para alguns ele vêm cumprindo essa finalidade, para outros ele carece de um "amadurecimento institucional". O fato é que todos têm apontado certa dificuldade no que tange a aplicabilidade de suas decisões e um (re)conhecimento da sociedade. A própria visão de uma ex-Secretária do Meio Ambiente, colocando o Conselho como órgão superior, corrobora com essa dificuldade de reconhecer sua importância e acrescenta que ela se expande mesmo até a perspectiva da institucionalidade dos poderes constituídos.

Ao segundo questionamento efetuado correspondente a relação entre o Conselho e o Poder Executivo, principalmente no que tange as três grandes crises que ocorreram (lixão, retirada do fundo e antenas), constatou-se que os fatores apontados giram muito nesta questão apontada anteriormente sobre a falta de reconhecimento institucional do Conselho.

Atenta-se, assim, que o centralismo político, a complexidade da administração pública, a falta de reconhecimento institucional do Conselho e 
também a falta de habilidade dos conselheiros na administração de conflitos internos ${ }^{5}$, foram alguns fatores que determinaram a crise entre o CONDEMA e o Poder Executivo (e também, em menor escala, com o Poder Legislativo). Porém, o aspecto que destacamos como mais forte nessa crise, refere-se à permanência de uma "cultura política" incapaz de estabelecer uma relação (institucional) com um novo mecanismo de gestão pública. A perda de poder deliberativo da classe política talvez seja o maior entrave no que se refere à inserção efetiva dos conselhos gestores nas administrações públicas. O grande fator de resistência política aos conselhos está relacionado com a natureza de suas atribuições, especialmente o seu caráter deliberativo, e não a sua existência.

Como visto, é realmente esse o fator que mais incomoda aos governantes, quando no desenho institucional dos conselhos consta por lei a condição deliberativa, e as decorrências que tal procedimento acarreta. Sendo que

de um lado, constam-se nos estudos do Observatório (2007) as tentativas de governos conservadores de retirar tal poder dos conselhos existentes, mas de outro também o próprio governo federal iniciado em 2002 com discurso participacionista e ações de diálogo social, ao criar novos conselhos, thes atribuiu poderes apenas consultivos assim como assumiu a indicação de representantes da sociedade civil em diversos casos (Pontual: 2007).

Neste sentido é necessário chamar a atenção à distinção entre a definição do conceito de decisão e deliberação. Enquanto que "o conceito de decisão remete ao resultado de um processo que envolve a eleição ou escolha entre alternativas; a noção de deliberação diz respeito à qualidade do processo que leva à decisão" (Tatagiba e Teixeira apud Pontual: 2007). Nesse ponto, os conselhos como órgãos deliberativos precisam ter internamente uma assimetria no que condiz as informações e conhecimentos necessários para efetuar esse processo de deliberação. $\mathrm{O}$ risco apontado é quando determinados segmentos, especialmente os representantes dos órgãos governamentais, detenham de forma privilegiada esses conhecimentos.

A relação interna também foi um ponto de questionamento. O momento turbulento em que vivia o Conselho ficou muito explicito nas entrevistas e é possível sintetizar que, segundo a visão dos entrevistados sobre essa crise interna, ela se refere a uma crise relacional entre pessoas e não entre as instituições que compõem o Conselho. O seu caráter de pessoalidade no embate demonstra que, como apontou um dos entrevistados, criou-se um "ranço", principalmente em

\footnotetext{
${ }^{5}$ Como será melhor explicitado no ponto a seguir que trata da crise de relação interna do
} conselho. 
razão do tempo de convivência dos conselheiros, da falta de resolutividade e da ausência de respeito a alteridade. O autoritarismo também foi citado por alguns dos entrevistados como gestor dessa crise. E finalmente, outro elemento citado nas entrevistas corresponde ao fato de que, a própria condição de o Conselho ser uma arena institucional de debate e confronto de idéias, pode tornar-se um "palco de disputa de poder" sempre que o caráter de pessoalidade e de intolerância preponderar.

\section{CONSIDERAÇÕES FINAIS}

Para traçar algumas considerações finais acerca do objeto central dessa pesquisa, isto é, do Conselho Municipal de Defesa do Meio Ambiente de Santa Maria, considero importante, preliminarmente, elencar alguns aspectos deste artigo.

Os conselhos gestores têm surgido com o propósito de ampliação da democracia, mas tem enfrentado obstáculos que ratificam o quanto a tradição política tem obstruído a constituição de um Estado democratizado. O autoritarismo, a cooptação e o patrimonialismo, como visto, são vícios políticos que, enraizados em nossa cultura política, tendem a serem um grande empecilho para a aplicação exitosa desses novos mecanismos de gestão pública. Lembramos que a própria descentralização política e administrativa, uma esperança contida na nossa carta magna de 1988 como melhora da gestão pública, necessariamente não se tornou sinônimo de democratização, uma vez que esses "vícios políticos" também tenderam a se descentralizarem, atuando desse modo em outras esferas administrativas.

No que pese a legislação, é a constituição de 1988 que, apesar de ser um tanto quanto conservadora em alguns aspectos (leia-se ausência de uma boa reforma no sistema político), é quem referenda a possibilidade de avanços na democratização da "coisa pública", inclusão e participação da sociedade civil nos processos de gestão administrativa do Estado, bem como dos novos mecanismos de fiscalização e controle na atuação dos governantes que foram criados. A esse respeito, destacam-se as novas atribuições e autonomia funcional do Ministério Público, que, como visto, foi um importante parceiro do CONDEMA. E a própria descentralização fiscal, política e administrativa, que teve por metas restituir o pacto federativo e democratizar a administração pública, outro importante passo na constituição de um estado democrático e de direito.

No que diz respeito à democracia, cabe ressaltar que se a concepção pluralista Bobbio 1987; Dahl ,1997)de analise da democracia é importante, estabelecida como parâmetro de análise a forma, os procedimentos e as regras, salientamos o quão se torna imprescindível à análise que vai além dessa relação 
entre instituições e sistema político, e que focaliza, também, a sociedade civil com elemento presente nessa relação. A aceitação da existência de uma cultura política, em uma perspectiva habermasiana, como elemento capaz da resolução dos problemas políticos, cujo enfoque de análise da democracia perpassa o próprio eleitorado, com suas ações e atitudes, mensurando também acerca da qualidade da democracia em vigência, não pode ser descartável.

Torna-se, assim, válido consignar a constituição desse espaço público, a formação de uma esfera pública é imprescindível para a atuação da sociedade civil. Consoante a teoria habermasiana, é um espaço, distinto do Estado, onde os indivíduos podem, através do agir comunicativo, interagir e debater as suas demandas, politizando acerca de suas questões. Aceitando, desse modo, a presença de arenas mais consensuais e comunicativas que vão além das arenas institucionais onde prevalecem à ação estratégica e competitiva.

Registra-se aqui que, embora os conselhos possam não ser considerados como experiências novas no que tange a serem fóruns institucionalizados, nem historicamente no Brasil, tampouco na sua existência em outros países do mundo, no entanto, no que refere a sua vitalidade, disseminação, diversidade de atuação e envolvimento de participantes fazem de nosso modelo atual experiências únicas no mundo. A presença de representantes da sociedade civil organizada, que, em conjunto com representantes do Estado, possuem a condição de aconselhar, fiscalizar e/ou deliberar sobre as questões administrativas, compondo arranjos de forças plurais presentes em um espaço de gestão que esta além dos espaços governamentais ou mesmo da sociedade civil, fazem por si só uma experiência no mínimo instigante.

No estudo realizado sobre o CONDEMA de Santa Maria observamos que, ao longo do período pesquisado, aconteceram duas crises que culminaram com a renúncia de seu núcleo: a primeira, que se define por uma crise relacional externa, oriunda de conflito com o poder executivo; e a segunda, uma crise relacional interna, que envolveu diretamente os seus representantes.

No que tange a crise relacional externa, ou seja, aquela estabelecida com o Poder Executivo, destacam-se três momentos altamente conflituosos que marcaram esta relação, e, embora, tenham características diferenciadas - uma vez que a do lixão pode ser condicionada, sobretudo, a uma omissão; a da retirada dos recursos do fundo por atuação premeditada; e das antenas por uma questão de "competência e poder" -, é possível vê-las de forma linear e seqüencial. Em meu entendimento, esses conflitos e seus respectivos desdobramentos (com o envolvimento de outros atores institucionais) revelam o quanto houve uma significativa alteração no aspecto de reconhecimento institucional do Conselho. É possível afirmar, nesse sentido, que essas crises serviram como um suporte para sua auto-afirmação. 
No que tange a segunda renúncia do núcleo, distintamente da primeira, esta crise o debate estava voltado a uma crise interna com claras conotações de pessoalidade.

Diante do exposto, ressalto sobre o próprio ambiente interno desses fóruns de interlocução e deliberação. Condicionado a se estabelecer a partir de uma convivência entre interesses e visões múltiplas, os conselheiros estão sujeitos a deliberar, propositivamente, sobre posições que nem sempre convergem. Esta convivência, auspiciosamente, estabelece a necessidade de respeito à alteridade e de uma salutar convivência democrática.

Neste ponto, observamos que o desgaste nas relações do CONDEMA foi se acentuando ao longo do tempo, e vários fatores se apresentam: a dificuldade de se estabelecer um ambiente democrático, no que pese principalmente ao respeito a opiniões divergentes, elemento imprescindível na produção de uma "arena mais consensual e comunicativa"; a própria busca de "poder pessoal" também não pode ser descartada; mas, também, a própria pouca resolutividade do conselho, como foi apontado, seria outro elemento que corroboraria enormemente com a gestação dessa crise interna.

Esta pouca resolutividade entra em total sintonia com a afirmação de que a recusa dos governantes está muito mais voltado a sua condição de deliberar e não propriamente a sua existência. A esse respeito convém refletir sobre os aspectos que remeteriam e essa pouca aplicabilidade das decisões do conselho.

Como visto, a causa ambiental não é considerada prioritária nos governos, haja vista, a necessidade de enorme investimento e o seu pouco "retorno eleitoral". No caso do CONDEMA isso não se fez diferente, as muitas mudanças dos secretários da pasta que trata do meio ambiente e as dificuldades apontadas pela ex-secretária demonstram claramente isso. Se a própria dificuldade de constituir uma secretaria instrumentalizada para atuar no meio ambiente foi registrada, seria no mínimo incongruente se pensar que as decisões do conselho seriam amplamente aplicadas. Ficando explícito, desse modo, certo descaso da classe política no que tange a causa ambiental. Entretanto, também é possível que essa falta de resolutividade se dê em razão da "cultura política" de nossos governantes, com a recusa em aceitar dividir o poder com estes novos fóruns institucionais de gestão pública. Embora sejam possibilidades distintas, elas certamente não se excluem mutuamente.

Sem ter por objetivo eximir ninguém de suas responsabilidades, muito antes ao contrário, cabe aqui a ressalva de que, embora a presença de partidos que estivam no governo esteja explícita, é preciso ponderar que este "problema" relacional com estes novos mecanismos vai muito além da simples partidarização, mas que, em minha visão, está intrinsecamente relacionado a sua própria cultura política de atuação.

Latitude, vol. 7, n², pp.169-190, 2011. 
A esse respeito convém frisar a distinção entre a relação estabelecida para com o Ministério Público e com os Poderes Executivo e Legislativo. O entrosamento constatado para com o primeiro difere consideravelmente da relação do conselho com o Poder Executivo e com o Poder Legislativo, onde o conflito se fez presente, o que corrobora com a perspectiva da dificuldade relacional com a classe política.

Analisando a partir da hipótese estabelecida, na qual: "as políticas ambientais, por requererem um alto investimento sem um retorno a curto prazo com fins ao mercado eleitoral -, limitam as ações do poder público às políticas 'maquiadas' e ao não enfrentamento dos reais problemas do meio ambiente, neste sentido, existe um esforço em condicionar o funcionamento e as deliberações do CONDEMA aos interesses do Poder Executivo"; observa-se que ela não pode de modo algum ser descartada.

Se por outro lado, inferimos que: "o CONDEMA foi criado como mais um instrumento arrecadatório ao município pela "classe política", que não tem o interesse em democratizar as deliberações acerca das políticas públicas do meio ambiente; ela certamente pode referendar-se com um caráter de validade.

Considero, portanto, que ambas possuem consonância com o que foi "levantado" por meio da pesquisa empírica sobre o Conselho.

De qualquer modo, considero importante investir nestes novos mecanismos de democracia, pois, substancialmente, os frutos que se podem colher, em caso de sucesso, mesmo que a longo prazo, são incalculáveis. De outro modo, no caso de fracasso deste tipo de mecanismo, o aprendizado e a experiência são, por si só, mais um passo no processo de maturação democrática, especialmente tendo em vista que, no caso do Brasil, a experiência democrática ainda é muito pequena. $\mathrm{O}$ que vale tanto para a estrutura tradicional de democracia, no caso da escolha de seus representantes no processo eleitoral, quanto para as novas formas de democracia. Além disso, a forma "pactual" que se estabeleceu a transição para a democracia após o último regime de exceção, cujo alcance se limitava apenas à esfera política, não alcançando as esferas econômica, social e cultural, só ratifica a necessidade dessa tentativa.

E o CONDEMA, apesar das dificuldades encontradas, tem demonstrado ao longo de sua história que está em um processo de auto-afirmação e amadurecimento. Sua capacidade de fiscalização apresentada, como um novo mecanismo de accountability, o aprendizado sobre o funcionamento, as finanças, a legislação e os processos administrativas da gestão pública, correspondem a um importante passo na constituição de cidadania. Se pensá-lo desse modo (enquanto esse processo pedagógico), corrigindo as deficiências internas, no que condiz também a atuação de seus atores, e continuar buscando, mesmo que por medidas judiciais, o cumprimento de suas deliberações, terá todas as condições de ampliar ainda mais a democratização da gestão pública. 


\section{BIBLIOGRAFIA PESQUISADA}

ALBERTONI, Ettore. (1990). Doutrina da classe política e teoria das elites. Rio de Janeiro: Imago Editora.

ARAÚJO, Wagner F. G. (2001) Jürgen Habermas: estado, mercado e movimentos sociais. In: www.sapereaudare.hpg.ig.com.br/sociologia/texto05.html (18/04/2005 às 14h 40)

AVELAR, Lúcia. (1998) Elites políticas, o eleitorado brasileiro e perspectivas da democracia na década vindoura. In: A democracia como projeto para o século XXI. São Paulo: Konrad - Adenauer- Stiftung, Centro de estudos.

AVRITZER, Leonardo. (1995). Cultura politica, atores sociais e democratização. In: Revista Brasileira de Ciências Sociais, $\mathrm{n}^{\circ} 28$, ANPOCS.

BENEVIDES, Maria Victória. (1991). A cidadania ativa: referendo, plebiscito e iniciativa popular. São Paulo: Editora Ática.

BOBBIO, Norberto. (1990) Liberalismo e Democracia. São Paulo: Editora Brasiliense.

. (1987) O Futuro da Democracia: uma defesa das Regras do Jogo. Rio de Janeiro: Paz e Terra.

BOLZAN, Gilmar T. (2002) As transformações na relação entre o PT e o MNLM, no município de Santa Maria, no período de 1991 a 2002. Santa Maria: Monografia de Graduação em Ciências Sociais- UFSM.

(2006) Os Conselhos Gestores de Políticas Públicas no Brasil: surgimento, especificidades, limites e potencialidades. Monografia de Especialização em Pensamento Político Brasileiro - UFSM .(2008) Participação e Meio Ambiente: Um estudo de caso sobre o CONDEMA de Santa Maria/RS. Dissertação de Mestrado em Sociologia Política UFSC.

BREMAEKER, François (2001) Os conselhos municipais existentes no Brasil. Instituto Brasileiro de Administração Municipal. Série Estudos Especiais $n^{\circ} 23$, maio de 2001, Rio de Janeiro.

CARVALHO, Paulo Gonzaga, et al. (2004) Instrumentos de Gestão local e Meio Ambiente. II Encontro Anual da ANPPAS: Campinas.

CITTADINO, Gissele (2000) Constitucionalismo "Comunitário" no Brasil In: Direito e Justiça Distributiva: elementos da filosofia constitucional contemporânea. $2^{2}$ ed. São Paulo: Editora Lúmen Júris.

COHN, Gabriel. (1977) Sociologia: para ler os clássicos. Rio de Janeiro: Livros Técnicos e Científicos Editora.

CÔRTES, Soraya Vargas. (2005) Arcabouço histórico-institucional e a conformação de conselhos municipais de política públicas. Educar, $\mathrm{n}^{\circ} 25$, p. 143-174, Curitiba: Editora UFPR.

Latitude, vol. 7, n², pp.169-190, 2011. 
COSTA, Sérgio. (1999) Esfera pública e as medições entre cultura e política no Brasil. Revista Metapolítica, vol. 3, $\mathrm{n}^{\circ}$ 1, Cidade do México. In: www.ipv.pt.formmedia/ fi $3 \mathrm{htm}(18 / 06 / 2005$ às $14 \mathrm{~h} 36)$

CUNHA, Eleonora. (2004) O potencial de conselhos no aprofundamento da democracia. $2^{\circ}$ Encontro de assistentes sociais com atuação em conselhos de políticas públicas - CRESS - MG. In: http://www.cress-mg.org.br/Textos/ CRESS\% 20encontro\%20conselheiros.pdf (24/03 às $12 \mathrm{~h} 50)$.

DAGNINO, Evelina (2004) Construção democrática, neoliberalismo e participação: os dilemas da confluência perversa. P. 137- 161. In: LÜCHMANN, Lígia e SHERER-WARREN, Ilse (org.) Política e Sociedade: Revista de Sociologia Política Dossiê: movimentos sociais, participação e democracia. Florianópolis: Cidade Futura.

- (2002) Sociedade civil, espaços públicos e a construção de democracia no Brasil: Limites e possibilidades. São Paulo: Paz e Terra.

FAUSTO, Boris. (2002). Historia do Brasil. 10ª ed. São Paulo: EDUSP.

FEDOZZI, Luciano. (1999). Orçamento Participativo: reflexões sobre a experiência de Porto Alegre. ${ }^{2}{ }^{a}$ ed. Porto Alegre: Tomo Editora, Rio de Janeiro: Observatório de Políticas Urbanas e Gestão Municipal (FASE/IPPUR).

FRISCHEISEN, Luiza Cristina Fonseca. (2004) Conselhos gestores e democracia participativa: o papel do Ministério Público. . In: www.dhnet.org.br/direitos/textos/ politicapublica/luizacf.html (08/08/2005 às 10h 16)

GOHN, Maria da Glória. (2004) Movimentos sociais: espaços de educação nãoformal da sociedade civil. In: www.universia.com.br/matéria (06/08/2004 às 21h). . (2000a) O papel dos conselhos gestores na gestão urbana. In: RIBEIRO, Ana Clara Torres (Compiladora). Repensando a experiência urbana da América Latina: questões, conceitos e valores. p. 175-201. Buenos Aires: Consejo Latinoamericano de Ciências Sociales - CLACSO / Agencia Sueca de Desarrollo Internacional - ASDI. - (2000b) Teoria dos Movimentos Sociais: paradigmas clássicos e contemporâneos. 2a ed. São Paulo: Edições Loyola.

GRISOTTI, Márcia ; PATRÍCIO, Zuleica. (2004) A saúde coletiva entre discursos e práticas: a participação de trabalhadores, usuários e conselheiros de saúde no município de Florianópolis. Florianópolis: Núcleo Transcriar.

GUTBERLET, Jutta (1996) Produção industrial e política ambiental: experiencias de São Paulo e Minas Gerais. São Paulo: Konrad-Adenauer-Stiftung, Centro de Estudos, Ano 1996, nº7.

HABermas, J. (1990) Pensamento Pós-Metafísico: estudos filosóficos. Rio de Janeiro: Tempo Brasileiro.

Paulo, n.36, p.39-53. (1995) Três modelos normativos de democracia. Lua Nova, Cedec, São

KRISCHKE, Paulo (1996) Brasil : Democracia "delegativa"? In: PINTO, Céli Regina e GUERREIRO, Hugo. América Latina: O desafio da democracia nos anos 90. 
Porto Alegre: UFRGS- Editora da Universidade / Associação de Universidades Grupo Montevideo.

LEFF, Enrique (2004) Saber Ambiental: sustentabilidade, racionalidade, complexidade, poder. $3^{\mathrm{a}}$ ed. Petrópolis/RJ: Vozes.

LUBAMBO, Cátia Wanderley. (2002). Conselhos Gestores e desempenho da Gestão nos municípios: potencialidades e limites. Fundação Joaquim Nabuco. Trabalhos para discussão, $\mathrm{n}^{\circ} 149$. In: www.fundaj.gov.br.tpd. (06/08/2004 às 21h 18)

LUCHMANN, Lígia. (2002a) Os conselhos gestores de políticas públicas:desafios do desenho institucional. Revista de Ciências Sociais Unisinos, n.161, p.43-79.

. (2002b). Possibilidades e Limites da Democracia Deliberativa. Tese de Doutorado em Ciência Política da Unicamp.

LÜCHMANN, Lígia e SHERER-WARREN, Ilse (2004) Situando o debate sobre movimentos sociais e sociedade civil. In: LÜCHMANN, Lígia e SHERER-WARREN, Ilse (org.) Política e Sociedade: Revista de Sociologia Política -Dossiê: movimentos sociais, participação e democracia. Florianópolis: Cidade Futura.

MARTINS, Luciano. (1988) A 'liberalização' do regime autoritário no Brasil. In: O'DONNELL, G., SCHMITTER, P. e WHITEHEAD, L. (org.) Transições do regime autoritário. São Paulo: Vértice.

MORONI, Antônio José. (2005). Participamos, e daí? Agência Ibase. In: www. Ibase.br/pubibase/cgi/cgilua.exe/sys/start.htm - (07/01/2006 às 16h 32m.)

OLIVEIRA, Juarez; OLIVEIRA, Ana Claudia Ferreira (1998) Constituição de 1988. São Paulo: Editora Oliveira Mendes.

PEREIRA, Adriana Freire. (2003). Ensaios de uma participação cidadã. Par'aiwa, $\mathrm{n}^{\circ} 4$, setembro de 2003, João Pessoa.

PEREIRA, Óthon F. (1998) Participação politica, interesses materiais e novas concepções de cidadania. In: BAQUERO, Marcelo, CASTRO, Henrique C. O., GONZALES, Rodrigo S. A construção da democracia na América Latina. Porto Alegre: UFRGS- Editora da Universidade / La Salle - Centro Educacional La Salle de Ensino Superior.

PINTO, Céli Regina Jardim (2004) A sociedade civil "institucionalizada". In: LÜCHMANN, Lígia e SHERER-WARREN, Ilse (org.) Política e Sociedade: Revista de Sociologia Política - Dossiê: movimentos sociais, participação e democracia. Florianópolis: Cidade Futura.

PONTUAL, Pedro (2007) Desafios à construção da democracia participativa no Brasil: a prática dos conselhos de gestão das políticas públicas. In: http://www.polis.org.br/utilitarios/editor2.0/UserFiles/File/texto\%20pedro.pdf acessado em 10/07/2008.

SANTOS, Romualdo. (1999) Accountability. In: http://www.cgu.gov.br/sfclideias/ ideias/Accountability.htm - (11/05/06 às10h 24)

Latitude, vol. 7, n², pp.169-190, 2011. 
SCHUMPETER, Joseph. (1961). Capitalismo, Socialismo e Democracia. Rio de Janeiro: Editora Fundo de Cultura.

SCHWARTZMAN, Simon. (1988). Bases do Autoritarismo Brasileiro. Rio de Janeiro: Editora Campus.

TATAGIBA, Luciana. (2002). Os Conselhos Gestores e a democratização das políticas públicas no Brasil. In: DAGNINO, E. (org). Sociedade civil e espaços públicos no Brasil. São Paulo: Paz e Terra.

(2005). A Institucionalização da Participação: os Conselhos Municipais

de Políticas Públicas na cidade de São Paulo. In:
http://www.democraciaparticipativa.org/ (07/09/05 às13 h 25)

TONELLA, Celene. (2003). Conselhos municipais de políticas públicas participação e governança local. XI congresso de Sociologia, setembro de 2003, UNICAMP, Campinas.

Jornal:

Diário de Santa Maria.

Sites:

http://www.ipef.br/

http://www.mma.gov.br/

http://www.ibge.gov.br/

www.santamaria.rs.gov.br/

http://www.camara-sm.rs.gov.br/ 